\title{
The Epidemiological, Clinical and Therapeutical Aspects of the Vesico-vaginal Fistula at the National Fistula Treatment Center in N'Djamena
}

\author{
Ache Haroun ${ }^{1}$, Mahamat Ali Mahamat ${ }^{1, ~ *, ~ S a l e h ~ A b d e l ~ S a l a m ~}{ }^{1}$, Haway Cherif ${ }^{1}$, Mohamed Jalloh ${ }^{2}$, \\ Lamine Niang ${ }^{2}$, Serigne Ma Gueye ${ }^{2}$ \\ ${ }^{1}$ Faculty of Health Sciences, University of N'Djamena, N'Djamena, Chad \\ ${ }^{2}$ Faculty of Medicine, University of Cheikh Anta Diop, Dakar, Senegal
}

Email address:

doctaali@yahoo.fr (M. A. Mahamat)

${ }^{*}$ Corresponding author

\section{To cite this article:}

Ache Haroun, Mahamat Ali Mahamat, Saleh Abdel Salam, Haway Cherif, Mohamed Jalloh, Lamine Niang, Serigne Ma Gueye. The Epidemiological, Clinical and Therapeutical Aspects of the Vesico-vaginal Fistula at the National Fistula Treatment Center in N'Djamena. International Journal of Clinical Urology. Vol. 4, No. 1, 2020, pp. 34-38 doi: 10.11648/j.jjcu.20200401.18

Received: March 11, 2020; Accepted: April 2, 2020; Published: April 30, 2020

\begin{abstract}
The objective of our study was to report on the epidemiological and etiopathogenic aspects of obstetric fistulas and to evaluate the results of their management at the National Fistula Treatment Centre in N'Djamena (Chad). Patients and Methods: This was a retrospective, descriptive study conducted at the National Fistula Treatment Centre in N'Djamena over a 4-year period from January 2012 to December 2016. Results: The mean age of our patients was 26.38 years with extremes of 12 to 74 years. The majority of our patients were young women aged 12 to 22 years. Of the patients $82.5 \%$ resided in rural areas. They were housewives in $88.9 \%$ and victims of genital mutilation in $76.8 \% .73 .6 \%$ did not have a prenatal consultation. A vaginal delivery was recorded in $74.9 \%$. Perinatal infant mortality was recorded in $83.2 \%$. Spinal anaesthesia was used in $95.7 \%$ of cases. The repair by low way in $93.7 \%$. The success rate in a so-called first-hand fistulas was noted in $88.88 \%$. Conclusion: Obstetrical fistulas is a real public health problem in our countries. Women with fistula are victims of all forms of social exclusion. The most effective means of combating it remains prevention and access to emergency obstetric care.
\end{abstract}

Keywords: Fistula, Obstetrical, Epidemiological, Clinical, Therapeutic, National Fistula Treatment Centre

\section{Introduction}

Obstetrical fistula is an abnormal acquired communication between the urinary and genital tracts or between the genital tract and digestive system. It generally occurs due to the bruising or compression of the pelvic organs by the foetus during an obstructed labour [1-3]. Vesico-vaginal fistula cases rarely do exist in the Western World while they are very common in developing Countries of Africa, Asia and South America. Vesico-vaginal fistula is the main public health challenge in the African continent. The World Health Organization (WHO) estimates up to 2 to 3.5 millions women survivors of the obstetric fistula only in Africa [4]. It acts as a barometer on inequality accessing maternal health care in poor countries. The goal of this article was to report our experience treating the obstetrical fistula at the National Fistula Treatment Center in N'Djamena (Chad) and to analyze it's epidemiogical, etiological and therapeutical aspects in order to promote a better treatment.

\section{Patients and Methods}

It was a retrospective and descriptive study carried over five years from January 2012 to December 2016. A total of 702 women surgically treated from obstetrical fistula had been collected. Were not included in our study all non obstetrical fistula and urinary incontinence cases. The different variables included: 
1. Socio demographic characteristics such as age, education level, destination, professional level and the point of view of the husband.

2. Obstetrical aspects: obstetrical background, pregnancy monitoring, conditions and type of delivery and the new born condition.

3. Clinical aspects: female genital mutilations, type of fistula and the tissue condition.

4. Therapeutical and prognosis aspects: type of anesthesia, the kind of surgical procedure, duration of the vesical catheter and the results in the short term.

Our data have been collected and analyzed through SPSS 18.0 software. We have used average frequency and our numbers were statistically significant for $\mathrm{a}=5 \%$.

\section{Results}

Table 1. Socio-demographic characteristics.

\begin{tabular}{lll}
\hline Variable & Value & \% \\
\hline Age (years) & 297 & 42,3 \\
$12-22$ & 271 & 38,6 \\
$23-33$ & 86 & 12,3 \\
$34-44$ & 31 & 4,4 \\
$45-55$ & 15 & 2,1 \\
$56-66$ & 2 & 0,3 \\
$>66$ & & \\
Destination & 123 & 17,5 \\
Urban & 579 & 82,5 \\
Rural & & \\
Education level & 600 & 85,5 \\
Non-schooled & 102 & 14,5 \\
Schooled & & \\
Matrimonial statut before fistula & 698 & 98 \\
Married & 6 & 0,9 \\
Divorced & 7 & 1 \\
Widows & 1 & 0,1 \\
Singles & 195 & 70,4 \\
Situation matrimoniale après fistule & & 0,1 \\
Married & 494 & \\
Divorced & 12 & \\
Widows & & \\
Singles & & \\
\hline & & \\
\hline
\end{tabular}

The fistula treatment was $62.5 \%$ of the surgical activity of this center. The distribution of the ages has been reported into table 1 . The average age of our study was 26.38 years with extremes of 12 and 74 years. The 12-22 years age group was the mainly affected with a total frequency of $42.3 \%$. The majority of the patients with up to $82.5 \%(n=579)$ were living in rural area. Non schooled and abandoned women were respectively $85 \%(n=600)$ and $70 \%(n=491)$. In our study, muslim women were predominant with a total percentage of 78.7\%.

Medical history variable

Most of the patients were having their first pregnancy with a percentage of $63 \%(n=442)$. The majority with $73.6 \%(n=517)$ were not medically monitored during their pregnancy. The average time of the delivery labour was 4 days with extremes from 1 to 7 days. It was about 72 hours in $41.6 \%(n=292)$. The delivery has been made at home in $57.4 \%(n=403)$ and in a healthcare center in $42.6 \%(n=299)$. Post-vaginal delivery was in $74.9 \%(\mathrm{n}=526)$ and by $\mathrm{C}$-section in $25.1 \%(\mathrm{n}=176)$. At birth, stillbirths represented $83.2 \%(\mathrm{n}=584)$ and live births were $16.8 \%$ $(\mathrm{n}=118)$.

Age of the fistula

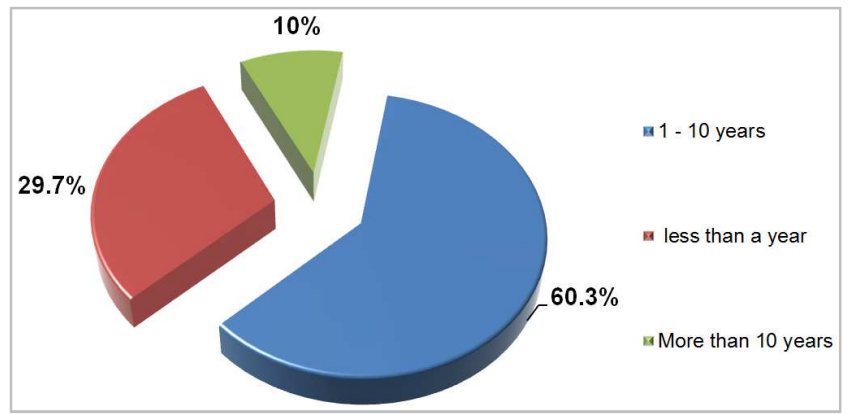

Figure 1. Age of fistula.

Figure 1 shows that $60.3 \%(n=423)$ of the patients have lasted with the fistula from 1 to 10 years.

History of fistula treatment

Table 2. Background of fistula treatment.

\begin{tabular}{lll}
\hline Number of treatment & Number of patients & $\mathbf{\%}$ \\
\hline None & 540 & 76,9 \\
Once & 68 & 9,7 \\
Twice to 3 times & 68 & 9,7 \\
$>4$ times & 26 & 3,6 \\
TOTAL & 702 & 100 \\
\hline
\end{tabular}

The Table 2 shows that $76.9 \%(n=540)$ of patients were at their first treatment.

Clinical aspects

The condition of the body tissue.

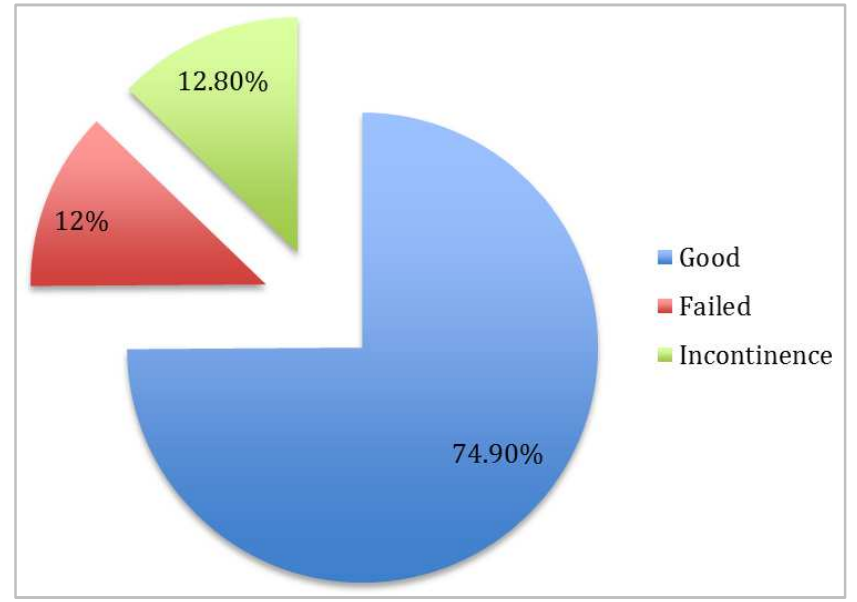

Figure 2. Distribution regarding the condition of the peri-fistula tissue.

The soft body tissue has been represented in $73.1 \%$ $(\mathrm{n}=513)$.

The localisation of the fistula

Table 3. Distribution regarding the localisation of the fistula. 


\begin{tabular}{lll}
\hline Localisation & Number & $\mathbf{( \% )}$ \\
\hline Vesico-vaginal fistula & 523 & 74,5 \\
Vesico-uterine fistula & 107 & 15,2 \\
Uretero-vaginal fistula & 15 & 2,1 \\
Recto -vaginal fistula & 36 & 5,1 \\
VVF + RVF & 21 & 3 \\
Total & 702 & 100 \\
\hline
\end{tabular}

The main localisation of the fistula pointed out in our study was the Vesico-vaginal with a rate of $74.5 \%(n=523)$. Vesico-uterine fistula was in $15.2 \%$.

Therapeutic aspects

The rachis anaesthesia was carried out in 95.7\% $(n=671)$ of patients.

Surgical procedure

The main surgical procedure used was vaginally with a total rate of $93.7 \%(n=658)$ followed with the abdominal procedure in $6 \%(\mathrm{n}=42)$ and both of procedure in $0.3 \%$ $(\mathrm{n}=2)$.

Associated gesture

Table 4. Distribution of associated gesture.

\begin{tabular}{lll}
\hline Associated gesture & Number & $\mathbf{( \% )}$ \\
\hline None & 641 & $91,06 \%$ \\
Re-implantation & 12 & $1,7 \%$ \\
Lithotomy & 15 & $2,13 \%$ \\
Perineum repair & 34 & $4,84 \%$ \\
Total & 702 & 100 \\
\hline
\end{tabular}

The Table 4 shows that the associated gestures were $8.6 \%$ $(\mathrm{n}=60)$. The duration of hospitalization was about 3 weeks in $52.4 \%(n=368)$ of our patients. It was about 2 weeks in $47.6 \%$ $(n=334)$.

Results in the short term

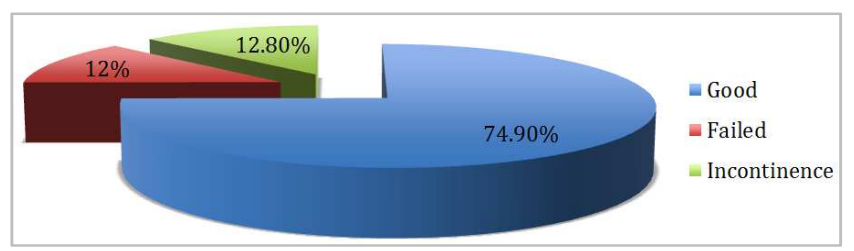

Figure 3. Immediate post-surgery results.

Post-surgical immediate result was good in $74.9 \%$ $(\mathrm{n}=525)$.

Results based on the classification

Table 5. Results based on the classification.

\begin{tabular}{llllll}
\hline $\begin{array}{l}\text { Short term } \\
\text { results }\end{array}$ & \multicolumn{2}{l}{ Classification } & \multirow{2}{*}{ Total } & \multirow{2}{*}{$\mathbf{P}$} \\
\cline { 2 - 4 } & Simple & Complex & Severe & & \\
\hline Good & 321 & 141 & 64 & 526 & \\
Failed & 42 & 25 & 19 & 86 & \\
Urinary & 51 & 26 & 13 & 90 & 0,11 \\
$\begin{array}{l}\text { Incontinence } \\
\text { Total }\end{array}$ & 414 & 192 & 96 & 702 & \\
\hline
\end{tabular}

In simple fistula cases, the full recovery rate was $77.53 \%$ $(n=321)$. Complex fistula cases rate was $73.3 \%(n=141)$ and severe fistula cases were about $66.6 \%(n=64)$ in Board V.

Results based on the background of fistula treatment
Table 6. Results based on the background of fistula treatment.

\begin{tabular}{|c|c|c|c|c|c|}
\hline \multirow{2}{*}{$\begin{array}{l}\text { Background of } \\
\text { fistula } \\
\text { treatment }\end{array}$} & \multicolumn{4}{|c|}{ Classification } & \multirow{2}{*}{$\mathbf{P}$} \\
\hline & Simple & Complex & Severe & Total & \\
\hline None & 327 & 148 & 65 & 540 & \multirow{6}{*}{0,11} \\
\hline Once & 33 & 18 & 17 & 68 & \\
\hline Twice & 26 & 8 & 7 & 41 & \\
\hline 3 times & 14 & 8 & 5 & 27 & \\
\hline $\begin{array}{l}4 \text { times and } \\
\text { more }\end{array}$ & 14 & 10 & 2 & 26 & \\
\hline Total & 414 & 192 & 96 & 702 & \\
\hline
\end{tabular}

We have registered a success rate of $75.55 \%(n=327)$ in simple fistula cases.

\section{Discussion}

\subsection{Epidemiological Variables}

\section{Frequency}

The fistula treatment has represented $62.5 \%$ of the surgical activity of the National Fistula Treatment Center (NFTC). Our result is largely important than KAMBOU'S [5] in Burkina-Faso which was $38.25 \%$. This important rate in our study would be explained by the fact that the study has been carried out in a national setting where all fistula patients are sent to.

Age

The average age found was 26.38 years with extremes of 12 and 74 years. This result can be compared to those highlighted by BOUYA in Congo [6] and TAYLOR SMITH in Burundi [7], respectively 28 and 31 years.

The 12- 22 years age group was the most common with a rate of $42.3 \%$. It is the moment of life where sexual intercourse is the highest.

Destination

The majority of our patients have been coming from rural area with a total rate of $82.5 \%$. BOUYA in DRC [6] and KABORE in Burkina -Faso [8] had registered lower rates than us with respectively $62 \%$ and $62.4 \%$. The main reason that explains our highest result would be that women in rural area are far from healthcare centers and lack means of transportation and by the way lack obstetrical care. This difficult condition tends to faster outbreak of fistula.

Socio-professional Class

Women without any profession were the most represented with $88.9 \%$. Our result is the same with KONAN'S [9] in Ivory Coast which was $88.57 \%$. Poverty and lack of education were relevant among women with fistula. The link between the low socio-economic and fistula has been established by many other authorsauthors $[7,8]$.

Religion

In our study, muslim women were the most represented group with $78.7 \%$. The reason would be that muslim population is the majority in Chad and they tend to send their daughters to early marriage.

Educational level

Our study showed up that most of the patients were not schooled with a rate of $85.5 \%$. This result is higher than 
DIALLO'S [10] in Guinea which has obtained $66.4 \%$. The difference may be explained by the fact that girls are not sent to school in our country. Instead, they are early prepared to take care of homes.

\section{Matrimonial statut}

The majority of our patients were married before having their fistula with a percentage of $98 \%$. But after being sick of fistula, $70.4 \%$ were divorced or abandoned by their husbands. CAPES [11] in 2011 has registered a result higher than ours: $87 \%$ cases of abandoned or divorced. One of the darkest social consequences of obstetrical fistula is the separation of partners because of the urinary incontinence with an unpleasant smell of urines coming from the patients.

Obstetrical history

Number of pregnancy

We have registered an important rate of $67.4 \%$ of first pregnancies. First time pregnancy were estimated to $50 \%$ in S. M GUEYE [12] and up to $61 \%$ of WAALDIJK [13].

Prenatal visit

Most of the patients have not been to prenatal visits for their pregnancy monitoring with $73.6 \%$. The reason would be the lack of knowledge on the importance of prenatal consultations in diseases prevention.

Duration of labour

The average time of labour observed in our patients was 3.11 days with extremes of 1 and 7 days. Our result has been higher than KAYONDO and all [14] in Uganda who have found an average time of labour of 2.5 days. This result shows up that the majority of our patients have not been receiving emergency obstetrical care earlier.

Place of delivery

Home delivery was the very common with $57.4 \%$ in our study. This result is higher than DIALLO'S which was $37.3 \%$ [10]. Home deliveries have been found by many other authors $[15,16]$. The situation may be explained by difficult living conditions of population characterized by extreme poverty, lack of means of transportation in many villages and other environmental barriers during rainy seasons. All these enumerated reasons may contribute to home delivery.

Type of delivery

Most of our patients have had vaginal delivery with $69.7 \%$. This type of delivery mostly occurs without any medical care and can be complicated with Vesico-vaginal fistula.

Newborn condition at birth

The rate of stillborn babies was $83.2 \%$ in our study. This result is lower than DIALLO'S and al [10] in Guinea in 2011 which was $91.1 \%$. This important stillborns rate may be explained by the fact that the obstructive labour constrains the foetal head and conduct to death by asphyxia.

Age of the fistula

Our results have shown that $60.3 \%$ of patients have spent 1 to 10 years with their fistula. This important rate points out the lack of informations regarding the different opportunities of fistula surgical treatment.

Background of fistula treatment

We have registered $76.9 \%$ of patients that were to their first surgical treatment. This rate can explain the impact of awareness on the chances of recovery.

\subsection{Clinical Variables}

Fistula type

In our specimen, Vesico-vaginal fistula were the most common in $74.5 \%$. Our result is lower than KAYONDO'S and al [14] in 2011 in Uganda which was $89.6 \%$.

\subsection{Therapeutical Aspects}

Type of anesthesia used

Rachis anesthesia was commonly used in $95.7 \%$. It is the most used type due to less side effects in patients.

Condition of the peri-fistula body tissue

The body tissue was soft in $73.1 \%$ of patients. This result is higher than the one found by QI LIYA [17] in Mali in 2000 which was $55.8 \%$.

Technique of surgical procedure

Most of surgical procedure has started vaginally in $93.7 \%$. This vaginal technique is the simple procedure that repairs Vesico-vaginal fistula by fortifying and stitching separately the vaginal and vesical parts after adjusting their sides. This surgical procedure has been inspired by CHASSAR-MOIR technique. Our result is the same found by OUTTARA [18] in Mali which was $89.5 \%$ of vaginal technique.

Duration of hospitalization

Fifty two percent $(52.5 \%)$ of our patients have spent 3 weeks and $47.6 \%$ a 2 weeks period at the hospital. A long hospitalization period has been pointed out by many different studies. Meanwhile, HAROUNA [19] has found very long months of in-patients.

Short term results

We have found a successful rate of healing of $74.9 \%$ but the failing rate is still as important as $12.3 \%$ of cases. Urinary incontinence cases represented about $12.8 \%$. These results are similar to those of KAYONDO [14] in Uganda and DIALLO [10] in Guinea who have found in 2011 respectively $76.4 \%$ and $79.3 \%$ of healing. The surgical treatment gives hope of best healing results especially for women with first time fistula. It also included to respect the rules of fistula surgery of COUVELAIRE: $<<$ Strive the best to have a successful surgery at first time because if the remaining fistula is often smaller than the original one, every surgery has its own risk of devascularisation and vaginal sclerosis mostly responsible of failure in the next surgical treatments.

\section{Conclusion}

Rarely found in developed countries, obstetrical fistula is a public health challenge in our developing countries. Women survivors of fistula are often facing social discriminations such as being abandoned, divorced, isolated culturally and religously. The level of education is an important factor that can make understand the disease. The treatment of fistula does not only give smile and hope but more importantly 
social reinsertion and chances to get married and have a normal sexual and obstetrical live.

\section{References}

[1] Camey M. Obstetrical fistulas. Edit. Progress in Urology 1998; Paris 328p.

[2] Couvelaire R. On vesico-vaginal fistulas (point of view). Journal of Urology 1984; 90: 507-508.

[3] Danso K A, Martey J O, Wall LL, Elkins TE The epidemiology of genitor urinary fistulae in Kumasi, Ghana. Int. Urogynecol. J. Pelvic Floor Dysfunct. 1996; 7: 117-120.

[4] OMS the prevention and treatement of obstetric fistula. Reportn of technical working groupe Geneva 17-21 April 1989 WHO/FHE 89.5.

[5] Kambou T, Zango B, Ouattara T A, Dao B, Sano D. Point sur la prise en charge des fistules urogénitales au CHU Souro des Bobo Dioulasso: Etude de 57 cas opérés en deux ans. Médecine d'Afrique Noire 2006 - 53 (12).

[6] P. A. Bouya, W. Itoua Nganongo, D. Lomina, L. H. Iloki. Étude rétrospective de 34 fistules uro-génitales d'origine obstétricale. Gynécologie Obstétrique \& Fertilité 30 (2002) 780-783.

[7] Tayler-Smith K, Zachariah R, Manzi M, Van den Boogaard W, Vandeborne A, Bishinga A et al. Obstetric Fistula in Burundi: a comprehensive approach to managing women with this neglected disease, in BMC Pregnancy Childbirth. 2013; Aug 21, 13 (1): 164p.

[8] F. Aristide Kabore, T. Kambou, A Ouattara, B Zongo, C. Yaméogo, B. Kirakoya, J. P. et al. Aspects épidémiologiques, étiologiques et impact psyco-social des fistules uro-génitales dans une cohorte de 170 patientes consécutives, prise en charge dans 3 centres du Burkina Faso de 2010-2012. Progrès en urologie. 24 ; 2014: 526-32.

[9] KonanPG1, Fofana A1, Kramo NF1, Vodi CC1, Gowe EE1,
Dekou AH1, OuegninGA1, ManzanK1, Nigue L1 LES fistules urogenitales dans le service d'urologie du CHU de Cocdy. Aspects évolutifs de 1990 à 2010. Uro-andro; 1 (3) 2015: 157-61.

[10] A. B. Diallo, T. Sy, M. D. Bah, T. M. O. Diallo, M. S. Barry, I. Bah et al, Fistule vésico-vaginales obstétricales en Guinée: analyse des données de trois sites de prise en charge de l'ONG engender health. 2011. Progrès en Urologie. 26, (3): 145-51

[11] Capes T, Asher-Walsh C, Abdoulaye I, Brodman M, Obstetric Fistula in low and middl-income contries MT sinai J Med 2011; 78: 352- 61 .

[12] Gueye SM, Ba M, Sylla C et al. Les fistules vésico vaginales: aspects épidémiologiques et thérapeutiques au Sénégal. J Urol 1992; 98: 148-151.

[13] Waaldijk K. Surgical classification of obstetric fistulas. Inter J Gynaecol Obstet 1995; 49: 161-163.

[14] Kayondo M, Wasswa S, Kabakyenga J, Mukiibi N, Senkungu J, Stenson A et al. Predictors and out come of surgical repair of obstetric fistula at a regional referral hospital, western Uganda, J Urol. 2011; 7: 11-23.

[15] LE Guyader A., Kebe M. Les fistules vésico-vaginales. Méd. Afr. Noire 1977, 475-481.

[16] D. Zoung, Kany, M. Sow. Le point sur les fistules vésicovaginales à l'Hôpital Central de Yaoundé à propos de 111 cas.

[17] QI Li Ya, Z. Ouattara, K. Ouattara. Traitement des fistules vesico-vaginales à l'Hôpital de Kati - a propos de 34 cas. Médecine d'Afrique Noire: 2000, 47 (3).

[18] K. Ouattara M. L. Traoré C. Clisse Traitement de la fistule vesico-vaginale Africaine (FVV) en Republique du Mali Experience du service d'urologie de l'Hôpital point $G$ Bamako (A propos de 134 cas) Médecine d'Afrique Noire: 1991, 38 (12).

[19] Harouna Y D, Maikano S, Djambeidou J, Sangare. A La fistule vésico-vaginale de cause obstétricale: enquête auprès de 52 femmes admises au village des fistuleuses. Méd. d'Afr. Noire 2001; 48: 57. 